\title{
Systematic Grant and Funding Body Acknowledgment Data for Publications: An examination of new dimensions and new controversies for bibliometrics
}

Link to publication record in Manchester Research Explorer

Citation for published version (APA):

Rigby, J. (2011). Systematic Grant and Funding Body Acknowledgment Data for Publications: An examination of new dimensions and new controversies for bibliometrics. (MBS Working Papers; No. 611).

\section{Citing this paper}

Please note that where the full-text provided on Manchester Research Explorer is the Author Accepted Manuscript or Proof version this may differ from the final Published version. If citing, it is advised that you check and use the publisher's definitive version.

\section{General rights}

Copyright and moral rights for the publications made accessible in the Research Explorer are retained by the authors and/or other copyright owners and it is a condition of accessing publications that users recognise and abide by the legal requirements associated with these rights.

\section{Takedown policy}

If you believe that this document breaches copyright please refer to the University of Manchester's Takedown Procedures [http://man.ac.uk/04Y6Bo] or contact uml.scholarlycommunications@manchester.ac.uk providing relevant details, so we can investigate your claim.

\section{OPEN ACCESS}




\section{Working Paper Series}

\section{Systematic Grant and Funding Body Acknowledgement Data for Publications: An Examination of New Dimensions And New Controversies for Bibliometrics}

John Rigby

Manchester Business School Working Paper No 611

\section{Manchestier Business School}

Copyright (c) 2011 Rigby, J. All rights reserved.

Do not quote or cite without permission from the author.

Manchester Business School

The University of Manchester

Booth Street West

Manchester M15 6PB

$+44(0) 1613061320$

http://www.mbs.ac.uk/research/workingpapers/

ISSN 0954-7401

The working papers are produced by The University of Manchester - Manchester Business School and are to be circulated for discussion purposes only. Their contents should be considered to be preliminary. The papers are expected to be published in due course, in a revised form and should not be quoted without the authors' permission. 


\title{
Author(s) and affiliation
}

\author{
John Rigby
}

University of Manchester

Oxford Road

Manchester

M13 9PL

Email: John.Rigby@manchester.ac.uk

\begin{abstract}
Bibliographic databases are beginning to provide systematic grant and funding body acknowledgement data for the publications they index. This paper considers how this new data might be used for policy purposes and the key issues that are likely to arise in its use. While the attempt to provide this kind of systematic data is in its relative infancy, there is already sufficient information within the WOS database to examine a number of controversies in science studies. This paper considers one such issue, namely the relationship between the number of funding sources acknowledged and the citation impact of publications where a positive relationship has been assumed to exist. Analyses of sets of publications from 2009 from the journals Cell and Physical Review Letters give contrasting results, suggesting that our understanding of the issue of the relationship between the impact of a publication and the number of funding sources which it acknowledges is not fully understood and may be more complicated that previously considered. It is proposed that scientific research findings are packaged by researchers into papers in a variety of ways for a wide variety of purposes. Individual funding quanta from whatever source are not therefore inputs to papers directly; rather, such funding supports a process that has amongst its outcomes, the production of papers.
\end{abstract}

\section{Keywords:}

Funding acknowledgement, grant, research, citation, impact

\section{JEL Classification}

\section{How to quote or cite this document}

Rigby, J (2011). Systematic Grant And Funding Body Acknowledgement Data For Publications: An Examination Of New Controversies for Bibliometrics.. Manchester Business School Working Paper, Number 611 available: http://www.mbs.ac.uk/research/workingpapers.aspx 


\section{Introduction}

Within the last few years, Thomson Reuters has begun to expand the information it gives in its Web of Knowledge about the funding sources which those who publish scientific papers have acknowledged as contributing in some way to their work. This new data now comprises three (not two Lewison, G. (2009)) new fields of information, the first identifying the funding bodies supporting the research (FO), the second (FG) providing a searchable text field giving the grant number and the third (FT), a searchable text field giving more detailed acknowledgement of the source of funds, providing scope to a paper's authors to explain how the funds were employed. Developments in this area have long been anticipated with discussions on the conventions of giving acknowledgements and proposals to automate the process of generating such information automatically being made by Giles, C. L. and I. G. Councill (2004) as long ago as 2004.

There is now a considerable amount of new data emerging and its possibilities will lead to new forms of bibliometric analysis. In the absence of large quantities of data from a long period of time within ISI on which bibliometric analysis can presently be performed, it seems relevant to consider what new data is going to be available, what methods might be used to analyse the bibliometric data that contains this new information, the purposes to which these methods might be put, and what implications are likely to arise for policy and academic practice. An analysis of papers from the journals Cell and Physical Review Letters is carried out on papers from 2009 to elaborate some of the possibilities of the new data and to shed light on a current controversy in science studies. 
While academic papers have contained information about funding acknowledgements for some time, it is only recently that this information has become available in such bibliographic databases as SCOPUS and the Web of Knowledge. Even so, such data is not yet available for all papers in these databases. A process of adding this information about funding acknowledgements to the existing papers is underway but is not yet complete. When complete, the following three fields of information will be available for each paper in the Web of Science: the funding organisation, a grant number and a text field giving a fuller explanation of how the funding was used. As Lewison notes Lewison, G. (2009) "fields are searchable as if they were paper titles, and both can be downloaded to file along with other bibliographic data." A more limited coverage of funding source / grant acknowledgement will be provided by Scopus limited to publications that enter the database after April 2010.

\section{Previous Use of Data on Funding}

In research evaluation, data about the funding has used been extensively in the past to define sets of papers that can be further analyzed for a variety of purposes but mainly to establish their performance in absolute and or relative terms. Such datasets that designate papers as arising from a particular grant or funding body have been created by research funders from their own records to examine the performance of the researchers they fund against a variety of benchmarks, for example against journal or field averages or the research papers of other funding bodies, for example Claveria, L. E., E. Guallar, J. Cami, J. Conde, R. Pastor, J. R. Ricoy, E. Rodriguez-Farre, F. Ruiz-Palomo and E. Munoz (2000). Papers defined in this manner and for such studies have often been assumed by research funders to be funded solely by one organisation. But, as the authors of papers are making clear when they provide information about the funding of their papers, and which is being captured by scientific 
indexing services, papers usually have acknowledgements to more than one funding body, and in many cases, to a large number of different bodies.

Where there has been attention paid to data on the funding of papers in the past, other than to define a set of papers that were the result of funding from one funding body, a number of pre-occupations have been evident, although the approach has been mainly limited to the application of descriptive methods. We examine the research evaluation literature and the broader science studies literature to reveal the major issues of interest. There are two main areas of work, evaluation studies and a more critical science studies approach.

In the area of research evaluation and funding policy formulation, there has been an auditing approach whereby investigation of the citation record has been undertaken to determine if funded authors had produced any publications (Albrecht, 2009). Research funders have also commissioned work from bibliometricians to examine how much funding a particular field has been receiving and what the patterns of funding have been Dorsey, E. R., P. Vitticore, J. de Roulet, J. P. Thompson, M. Carrasco, S. C. Johnston, R. G. Holloway and H. Moses (2006). Other work in this area has involved mapping funders to fields to show who is funding what area of science. This work has been carried out at a number of levels: in the case of specific disciplines, for example for malaria Maclean, M., Davies, C., Lewison, G., Anderson, J. (1998), gastroenterology Lewison, G. (1998), thoracic medicine Partridge, M. R., I. Rippon and G. Lewison (2003); at specific funding programme level, for example the biotechnology action programme of the EU - Lewison, G. (1994). Later work Boyack and Borner (2003), also focusing on research programme funding, has proposed the development of visual methods to portray the relationship between grants and publication.

More detailed and critical reviews within a broad science studies approach have explored issues such the conventions of acknowledgement giving Cronin, B. and S. Franks (2006) Bar-Ilan, J. (2008) Salager-Meyer, F., M. A. A. Ariza and M. P. Berbesi (2009), the frequency of occurrence of funding bodies and other entities such as authors in the acknowledgements to papers, Giles, C. L. and I. G. 
Councill (2004) including trends and changes in the occurrence of acknowledgements of particular bodies over time Giles, C. L. and I. G. Councill (2004). Such work has also been carried out by Cronin and Franks (2006) on the papers in the Journal Cell.

Studies of scientific activity that have looked at funding without using data on publications specifically but which nevertheless consider a link between funding and quality of research (i.e. studies that examine funding but which do not have a bibliometric dimension) include reviews of the importance of funding income as an indicator of research quality Gillett, R. (1991), the importance of previous funding as a basis on which to carry out future research Laudel, G. (2005), and on growth of university funding at the institutional level and comparability with business growth Plerou, V., L. A. N. Amaral, P. Gopikrishnan, M. Meyer and H. E. Stanley (1999).

Studies linking funding explicitly with the citation impact of papers include at the level of individual scientists work by Sandstrom (2009) on the relationship of the quantity of funding won by individual scientists and the citation impacts achieved by their work. However, a more ambitious programme of research has entertained the idea that the quantity of funding and the identity of funding sources are important influences upon the citation impact of papers because research funders generally implement some form of peer review over grant applications and this ultimately influences the impact of papers.

In the area of Library and Information Sciences (LIS), Zhao (2010) examines funded and normal research (i.e. non-grant funded research) published in the leading 7 journals of the field. His analysis concludes that while funded research is generally of higher impact, not all the very best ideas are generated from it because some of the most cited papers in his analysis are shown to be unfunded. The finding justifies his view that "it may therefore be crucial for the advancement of science to keep a good balance between grant-based research and normal research (i.e. non-grant funded research) when setting research policies" page 305 . This perspective on the LIS field is perhaps not easily generalized to other fields as in Zhao's dataset, only around a quarter of papers are funded by grants, while in the medical and biosciences fields, around only 5\% of papers are non-grant funded. The 
finding is however supported by some smaller scale studies of Nobel Laureates and their most important work Berg, J. M. (2008, Tatsioni, A., E. Vavva and J. P. A. Ioannidis (2010) which emphasize the absence of any link between funding in the form of specific grants and ground breaking research. There is however some extensive research directly examining the link between the number of sources of funding of a paper and impact has generally come to the view that the more sources of funding a paper received, the greater was its citation impact Lewison, G. (1994, (1998, Lewison, G. and G. Dawson (1998, Lewison, G., J. Grant and P. Jansen (2001). This line of argument has linked impact to the number of funding sources but without explicitly considering in detail the related issue of research collaboration, a practice linked to quality, but at the same time also potentially connected to the number of funding sources received by a paper.

The main contention of these studies in relation to the link between funding and impact is that the more often an individual research idea is successfully peer reviewed, which it would be if it were the subject of a grant application that was funded, the more plausible to peers it is and therefore the more likely it is to lead to research of higher quality. This important claim is one of a number of observations that deserve to be subject to more detailed scrutiny with the new funding data that is becoming available and later in this paper such an analysis is presented using 301 papers from the journal Cell in 2009 and 3414 papers from Physical Review Letters, also from the same year. The research presented here establishes on the basis of the data that the relationship between the number of funding sources acknowledged by a paper is not always closely related to its citation impact and any such relationship appears to be weak. Before this analysis is presented, consideration is made of the information now being made available by the WOS for bibliometric research and research evaluation and policy formulation. 


\section{Scope for Analysis of the New Data}

The provision of funding acknowledgement data in the bibliographic record may make possible a range of new forms of analysis. But those wishing to use the data need to take account of a number of issues concerning the interpretation of bibliometric data on funding which fall into two main classes: these are on the one hand problems arising from what might be called simple errors and confusion; and on the other more systematic biases affecting the quality and reliability of the data that results from various culturally bound and optimizing behaviour on the part of authors when they choose to acknowledge (or not) their sources of funds. Very similar kinds of issues are now raised therefore about funding acknowledgements as were raised in the 1970s and 1980s concerning the meaning of a citation.

\section{Limitations - simple errors and confusion}

The first source of simple error is likely to arise through the misspelling of the names of funding bodies and potentially the names of grants and grant codes. Current practice in the WOS is not to create standardized organisational names and or organisational codes. Consequently, the age old problem of identifying a specific entity is likely to reoccur and to make pre-processing of data before analysis essential. Such pre-processing might need to be very extensive, in that the data which is reported by authors in the citation record might need to be cross-checked with project reports submitted by authors to funding bodies as a double-check. That there is as yet no standardisation of organisational names is perhaps not surprising as funding organisations can change their names, although they do not do so regularly, and those which are most successful tend to hold on to theirs. Bodies that change their name most often are likely to be government departments. In the UK at least, departmental names have had a recent habit of changing whenever a ministerial reshuffle occurs. In the Web of Knowledge at present, the previous name of the trade ministry, BERR, only exists ten times, so we should perhaps be grateful that BERR is not a more prolific funder of research as it has 
now been renamed BIS. But those who search for BIS may find other organisations known by the same term, one example being the Bremerhavener Gesellschaft fur Innovationsforderung und Stadtentwicklung. Coverage by year and by funder is as yet incomplete. While the current Web of Knowledge contains an NIH funded paper from as early as 1965, there are many omissions.

A second difficulty will be that researchers will not correctly remember the funding bodies and grants that they used to support the research. When publication follows a long period after a grant, this problem will be more significant. When many grants are in use, the problem is worse still; and if the collaboration is a large one involving researchers from many centres, the problem becomes severe. Even when researchers can recall what grants they have obtained, and what work they have carried out, they must face up to the problem of attribution itself. The attribution problem is clearly one that should be referred to in this section which is more concerned with the technical difficulties of linking funding sources to publications; but such difficulties do underlie the second kind of problems and these are considered in the next sub-section.

Other technical issues that arise include the interesting anomaly that because grants can provide the opportunity to write up following the discovery, grants may apparently follow the research findings rather than the other way around. While most funding bodies would be reluctant to give awards for writing up, there are some that do. It may be useful to compare the date of any grant with the date given in the paper about when the research started. If a grant post dates the start of a research project, then it will be likely that the grant will have been used to write up. Problems multiply when there is more than one grant, an issue discussed in the next sub-section.

Many researchers may not have a specific grant with which they carried out their work but were supported by "core" funding, whether through block grants from external agencies such as, in the case of the UK, QR money from a funding council, or through institutional resources. It is likely that those providing core funding will be quick to press for core funding to be acknowledged on papers. These 
are the main reasons that will give rise to error in the record. In the next section, the cultural and political dimensions of acknowledgements are examined.

\section{Limitations - cultural and political}

Here we consider some of the issues facing researchers when they attempt to decide how to acknowledge their funding and where their behaviour may be affected by perceptions of self-interest. As has been noted above, many of these issues arise from the attribution problem, the lack of a solution to which creates scope for a range of behaviours discussed below. Thus, while funding acknowledgements may represent the direct debt of the authors of a paper to funding source à la Mertonian normative citation, it is possible if not indeed likely that the practice of citing of funding organisations will also be in the Latourian sense Latour, B. (1987). It is quite likely that some authors, keen to burnish their reputation with a particular high status funding will exaggerate the "productivity of certain grants"; conversely, they may also wish to obscure their funding from other less established and lower status funding bodies. Overall, it might be possible to see a tendency towards overattribution generally of sources to papers, with a greater rate of over-attribution to more high profile, high status grant awarding bodies.

When researchers acknowledge funding, they will not always know the order in which to provide their funding acknowledgements. Some may adopt the protocol of listing the acknowledgements in order of the perceived impact of the funding body upon the work, while others might wish to avoid such a prioritization, using alphabetical ordering, for example. Impact though is itself problematic as the ultimate success of a research activity in terms of publication may be seen to be more dependent upon the marginal grant. 
As many papers are written by multiple authors, each of which might conceivably be receiving multiple grants, there is a problem by which a consensus ordering of the funding bodies contributing to a paper can be reached. Even in the simple case of where two authors are reliant upon a grant, one may be solely dependent upon it, while the other may be reliant upon it to only a very minor degree and have other grants of much greater importance. Deciding the order of the funding bodies and grants in this instance would be difficult even if the contribution of authors was equal. If they were not equal, further complications arise which might make a rank ordering impossible.

Authors may of course agree about the role of different funding bodies in supporting research and yet find the issue of deciding a rank ordering of acknowledgements difficult if not impossible. But they may also disagree about which funding body was more important than another. This is quite likely.

Authors will also bring their own agendas with them to this process of attribution. The ordering of acknowledgements is not likely to be a merely retrospective exercise in deciding where the credit for funding a particular piece of research lay. Factors that affect how authors will wish to acknowledge funding will be the need to use citation for what might be influencing or political purposes. Perceived low status funding bodies may be left off the list of acknowledgements if it was felt that the acknowledgment of such funding might harm reputations. Conversely, high status funding bodies might find that they were listed on more of the papers of a group of authors than were genuinely produced with their help simply to enhance the reputation of the authors. It should also be noted that acknowledgement behaviour is to some degree affected by possible perceptions on the part of readers of the quality denoted by a high status funder. Authors might wish not to credit high status funding bodies if they believe that a publication was not their best work (although it would of course be good enough to achieve publication). As has been noted above in relation to core funding, researchers keen to hold on to their core funding are likely begin to acknowledge it. 


\section{Perspectives and Analyses}

The difficulties outlined suggest that the use of funding acknowledgements for a variety of purposes of bibliometric analysis could be highly problematic. A wide variety of unknown effects and unknown types of errors and are likely to affect the data. Nevertheless, there may be some scope to use funding acknowledgement information to venture some answers to important questions of impact and about the relationship between funding and the generation of scientific knowledge. The next three sections consider these issues in turn, beginning with the issue of error prevention, and then continuing to a discussion of issue of impact, and then to a discussion of the link between funding and generation of scientific knowledge.

\section{Preventing or Reducing Error}

Strategies for the removal of or reduction of error in the data before conducting analysis would appear firstly to justify inspection and scanning of the funding source data to ensure that there are not duplicate names, but types of error correction strategy would appear to vary depending upon the types of analysis to be carried out. Relatively simplistic analysis of data of counts of funding sources would require checking to ensure that sources were not duplicated within a particular paper, thereby ensuring that no paper had the same funding organisation reported more than once. Counts of grants received would also require the same form of correction. But where mapping of funding sources was to be carried out through the use of linking tables in relational databases and for network analysis, all misspelling of funding sources and or grants would need to be removed otherwise the correct mapping and cross referencing of funding bodies and or grants would not occur reliably.

The FO field could also be read in conjunction with the FG field, which gives the funding organisations acknowledged as supporting the work, to obtain clearer understanding of specific roles of individual funding bodies and their grants in the production of the work. However, authors have discretion in their use of both fields, but more especially in the FX field, and this may make it difficult 
to carry out systematic error checking using the two fields alone. Attempts to show that a particular funding organisation had supported a particular paper could be made by referring to funding body reports, the basis of the original approach to funding acknowledgements. Such an approach to error correction could be hugely time consuming if a data set included papers with many funding acknowledgements.

Questions about identity and the unit of analysis also arise when funding bodies change their names although they continue to perform the same activity, or when funding bodies remain the same but change the activities they carry out. Reference to the terms of reference of funding bodies may be required to resolve questions that concern the purposes of funding; while reference to the history of a funding body should be carried out determine whether the change of name conceals a common identity.

When analysing the funding acknowledgement data, the assumption should not be made that the count of funding bodies will be the same as the count of grants for all papers; in some cases one funding body may have supported the work reported in a paper with multiple grants. When examining the relationship between the count of funding sources and the impact upon publications, the question may arise whether to use the count of funding organisations or the count of grants as the measure to relate to the impact of the paper. Two basic choices may be considered here, either to count the funding bodies or to count the grants, but the problem is that funding bodies often have different kinds of grants, such that grants from two different funders may be more alike than two grants from the same funder. Thus, the counting of grants or the counting funding bodies that support a piece of work qua measures of the influences upon the impact of a published work through the mechanisms of peer review (see earlier discussion) is problematic. In the attempt to find a quantitative indicator of the extent of oversight and examination of the plans for research that has contributed to a particular publication, it would be sensible to allow each grant supporting a paper to count towards the indicator if the peer review processes of the funding body that provided the grant operate to different criteria; but if grant awards from the same funder operate to the same or very similar criteria, then each grant 
should not be counted separately towards the indicator. This approach would however require investigation of the peer review processes of every grant for every awarding body, a potentially very lengthy process.

Impact

The systematic collection of funding data within the WOS may facilitate a wide range of measures to assess the impact of individual funding bodies. It will be possible for funders to establish how many papers they may have funded and how many citations their funding is associated with. Funders may be able to determine to what extent their support goes to truly ground-breaking work. Such work is likely to be characterized by high number of citations, particularly in the longer term, but, if it is truly visionary, it is likely to have fewer funding acknowledgements. Citations of publications within patent claims would also be possible, making attempts to implement methodologies characteristic of such studies as TRACES more feasible Kreilkamp, K. (1971).

Funding bodies may begin to count their overall share of papers in a field which have had their support; similar measures for the share of citations are also possible. Being first into a new field will be as much a matter of pride and success for a research funder as for those carrying out the research and the institutions in which they work.

Comparisons of citations per paper by each funder will be problematic, like many of the measures mentioned immediately above, because papers have multiple funding acknowledgements. Papers funded exclusively by one funding agency are likely to be rare. Nevertheless, comparisons may be made between funders, and types or categories of funding bodies. Further attempts will be made to assess the cost of citation in particular fields, and the efficiency with which funders, and researchers, achieve citation impact. 
Further opportunities are also available to exploit funding data in conjunction with other bibliographic information. These opportunities arise from the relational database techniques that can exploit the phenomenon of co-occurrence in bibliographic data.

Co-occurrence provides a means of linking funding to fields and this may show which funders dominate a field, what proportion of a field is funded in any period (say a year) by a particular funding body and what proportion of the citations in a field is funded by a particular funding body? This could lead to various statistics of funder dominance. For example - the proportion of cites in a field divided by the proportion of papers in a given period. Such a factor - a $D$ (dominance) factor would show the dominance of a particular funder in a field. A Hirsch style indicator could also be adopted for each research funding body or its research programme to measure the impact of its funding.

It will also be possible to ascertain which funders are most closely aligned in terms of how their support is used by researchers. The question could then be answered, "Do these particular funders duplicate each other's work or do they provide competition?", an issue considered later in this paper.

Funders could also be assessed in terms of their support for a) interdisciplinarity b) collaborative research (number of organisations taking part, co-authorship) and perhaps also c) the internationality of the teams they fund.

Linking of papers to funding sources may give an answer to the question "Which other fields' papers cite work funded by a particular organisation?" This might give some sense of the broader impacts of research beyond the initial field of application and area or topic which a particular funding body seeks to support. 
It may also be possible to look at the issue of to what extent certain funders "own" a particular field, in that research within that area is to some extent limited to researchers funded by particular funding bodies. Such "ownership" might also be indicated through the extent to which citations in a field were to papers funded by the same sources as the cited papers.

Just as co-citation can show how papers are grouped together to create fields, so co-grant and field analysis can be used to show how grants join certain scientific fields together. The role of funding agencies in linking fields together can be more easily determined where the body funding the research is known as would be the case where the grant giving body was acknowledged on the publication record.

\section{Implications and Controversies}

Here we discuss some of the immediate implications of this new data and the analyses that will result. Firstly, the behaviour of funders is likely to become far more exposed. This may reveal that the research supported by funding bodies with contrary objectives or criteria (for example, a paper might result from grant from funding body A whose criteria are in some way different from and indeed in consistent with those of another funding body B which also supported the research). The performance of funders in a whole range of dimensions will be much more closely examined. Funders will know more about their own activities and about other key actors in the research landscape.

Analysis of the role of funding will be needed to investigate a number of questions to which answers would be useful for policy purposes. Such issues include the importance of grant funding to really key papers. Understanding of differences between fields in terms of the number of funding acknowledgements would be helpful for research policy purposes. Fields differ in terms of the number of articles funded. In fields where research is costly and where research requires grants to fund it, more papers are likely to show funding acknowledgements. In research fields where there are larger 
teams of authors, and where authors are funded by a range of bodies, increasing numbers of funding sources will be found on papers. In the LIS study reported by Zhao, D. Z. (2010), 27\% of papers noted one or more funding sources, while in Cell in 2009, 94\% of all articles acknowledged funding and in Physical Review Letters for the same year, $83 \%$ acknowledged funding. When funding becomes scarce, researchers may react by using their funds more flexibly; this may generally increase the number of acknowledgements on papers.

A further key issue is that of the relationship between the number of funders of a particular piece of research and its impact in terms of citations received. A small test of the relationship between the numbers of citation impact funding acknowledgements to research papers in the journal Cell and the journal Physical Review Letters in 2009 has been carried out. The details of this exploration are given in the next section.

\section{Analysis of the Number of Funding Sources and Citation Impact of Papers in the Journal Cell and the Journal Physical Review Letters in 2009}

\section{Method}

Papers from the journal Cell and the journal Physical Review Letters for the year 2009 were abstracted from the Web of Science. For the Cell papers 301 research articles (papers) out of a total of 646 publications were further examined to obtain their citation count and the number of funding acknowledgements they contained. Research articles from Physical Review Letters were also abstracted and 3414 papers were then reviewed to find their citation counts and the number of funding acknowledgements for each paper. For both of the journals, these two attributes of data were noted, as was the period of time elapsed from publication to the point where the citation count was taken. Research papers rather than reviews, book reviews or other types of paper were chosen as these might 
be expected to constitute different forms of academic work and have different patterns of funding acknowledgement or, in the case of book reviews, no funding acknowledgement data at all.

For the Cell papers (301 papers), and then for the Physical Review Letters papers (3414 papers) each paper's count of citations was correlated against the time elapsed since publication to rule out any possible effect that journal publishing policy might have upon the types of article published. Such an effect could then influence the relationship between the number of funding sources of a paper and its citation count. Analysis of neither journal found any correlation between the time elapsed from publication of the paper and the type of funding source. For both journals, there were papers that had not been cited and papers that had been cited many times (for Cell, the maximum was 173 cites, for PRL, the maximum was 209).

The age of a paper was defined in terms of the number of issues of the journal between the point when the paper was published and fixed point two years from the point of the first article published in 2009, a point at which the rate of increase in citation counts might begin to reduce. This period of time was the period in which the majority of citations to a paper would accumulate. The earlier the paper appears, the longer its lifetime and the more citations it would be expected to have. Lifetime was measured in terms of issues. It was not surprising that a statistically significant correlation (measured using Spearman's Rank correlation coefficient) existed between the age of the paper and the number of citations, but there was none between the age and the number of funding sources.

The purpose of the analysis was to examine the evidence from the data of these two pre-eminent journals that might support the view expressed by a number of authors Lewison, G. (1998, (2009, Lewison, G. and G. Dawson (1998, Lewison, G., J. Grant and P. Jansen (2001) that the number of funding sources indicates the level of peer review to which a piece of research has been subject. This previous research has generally concluded that the greater the number of funding acknowledgements of a paper, the greater is the likelihood that research quality, and therefore citation impact, will be higher. In carrying out this analysis, the choice was made to use the count of funding 
acknowledgements (i.e. funding bodies) rather than the number of grants on the assumption that it is the number of funding bodies that most indicates the variety and extent of the peer review process to which a research proposal is put, and is a more valuable of such an influence indicator to subject to a test.

Analysis

For both journals, the papers were arranged by count of funding source into groups of more than five to satisfy the assumptions of the Kruskall Wallis Test. The grouped papers were then ranked according to their citation counts of the members of each group. As the following figures and statistical test results indicate, the journal Cell and the journal the Physical Review Letters differ in that for the Cell papers from 2009 that were examined, no statistically significant relationship exists between the number of funding sources and citation impact of the papers; whereas for the Physical Review Letters, a positive relationship does exist between the number of funding sources of a paper and the citation impact, albeit a relatively weak one. It is suggested that the link between the number of funding sources and the impact of papers is more complex than has been assumed previously, and is therefore worthy of further investigation. These observations are by no means conclusive in that they do not provide strong evidence either way for the impact of the number of funding sources upon the citation impact of papers and may suggest the presence of differences between fields. The role of collaboration as a possible mediator between the count of funding sources and impact has not been taken into account here; such an analysis has been beyond the scope of this paper. Other potential sources of error such as possible the misclassification of journal articles at input to the Web of Science have not been investigated as this would have required inspection of each journal article.

Figure 1 about here 
Figure 2 about here

Table 1 about here

Table 2 about here

Table 3 about here

Table 4 about here

\section{Discussion and Reflection}

We note that, on the basis of the data presented here, the assumption that the number of funding sources which a paper cites is not invariably a reliable predictor of increased impact, and where such an impact can be found, the strength of the effect is very small. It could be argued that the view that the greater number of peer reviews involved with a piece of research does apply, but that an increasing number of funders associated with a piece of work will make the work more difficult to carry out. Thus, these two effects might counter-act each other, leading to the absence of any clear relationship between the number of funders and the research impact.

However, if it is the case that an increasing number of peer review processes (e.g. the number of . funding bodies) associated with a paper does not make a difference to impact, is there not then a case for suggesting that research funding bodies consolidate their activities? Research funding bodies would not appear to add anything to the quality of research, they just provide resources: so should not 
research funding bodies reduce the burden they place upon researchers by merging their quality control and grant awarding activities?

These suggestions about relationships between funding bodies and impact and the policy proposals that follow from them might be warranted if the simple input output model of funding bodies and papers was itself realistic. But we know that papers are a highly arbitrary unit of research output. Research findings are packaged by researchers into papers in a variety of ways for a wide variety of purposes. Funding sources are not simply an input to a paper but to a process which is managed by researchers. And this research process can produce its output in large number of ways depending upon a range of academic conventions and priorities. 


\section{References}

BAR-Ilan, J. (2008): "Informetrics at the Beginning of the 21st Century - a Review," Journal of Informetrics, 2, 1-52.

Berg, J. M. (2008): "A Nobel Lesson: The Grant Behind the Prize," Science, 319, 900-900.

BOYACK, K. W., and K. BORNER (2003): "Indicator-Assisted Evaluation and Funding of Research: Visualizing the Influence of Grants on the Number and Citation Counts of Research Papers," Journal of the American Society for Information Science and Technology, 54, 447-461.

Claveria, L. E., E. Guallar, J. Cami, J. Conde, R. Pastor, J. R. Ricoy, E. Rodriguez-Farre, F. RuizPalomo, and E. Munoz (2000): "Does Peer Review Predict the Performance of Research Projects in Health Sciences?," Scientometrics, 47, 11-23.

Cronin, B., and S. Franks (2006): "Trading Cultures: Resource Mobilization and Service Rendering in the Life Sciences as Revealed in the Journal Article's Paratext," Journal of the American Society for Information Science and Technology, 57, 1909-1918.

Dorsey, E. R., P. Vitticore, J. De Roulet, J. P. Thompson, M. Carrasco, S. C. Johnston, R. G. Holloway, and H. Moses (2006): "Financial Anatomy of Neuroscience Research," Annals of Neurology, 60, 652-659.

GILES, C. L., and I. G. CounCILL (2004): "Who Gets Acknowledged: Measuring Scientific Contributions through Automatic Acknowledgment Indexing," Proceedings of the National Academy of Sciences of the United States of America, 101, 17599-17604.

GILletT, R. (1991): "Pitfalls in Assessing Research Performance by Grant Income," Scientometrics, 22, 253-263.

Kreilkamp, K. (1971): "Hindsight and the Real World of Science Policy," Science Studies, 1, 43-66.

LATOUR, B. (1987): Science in Action: How to Follow Scientists and Engineers through Society. Milton Keynes: Open University.

LAUDEL, G. (2005): "Is External Research Funding a Valid Indicator for Research Performance?," Research Evaluation, 14, 27-34.

LEWISON, G. (1994): "Publications from the European-Community Biotechnology Action Program (Bap) Multinationality, Acknowledgment of Support, and Citations," Scientometrics, 31, 125-142.

— (1998): "Gastroenterology Research in the United Kingdom: Funding Sources and Impact," Gut, 43, 288293. 
— (2009): "Financial Acknowledgements on the Web of Science: A New Resource for Bibliometric Analysis," Rio de Janeiro.

— (2009): "Financial Acknowledgements on the Web of Science: A New Resource for Bibliometric Analysis," in Proceedings of Issi 2009 - 12th International Conference of the International Society for Scientometrics and Informetrics, Vol 2, ed. by B. Larsen, and J. Leta. Leuven: Int Soc Scientometrics \& Informetrics-Issi, 968-969.

LEWISON, G., and G. DAwson (1998): "The Effect of Funding on the Outputs of Biomedical Research," Scientometrics, 41, 17-27.

LEWison, G., J. Grant, and P. JANSEN (2001): "International Gastroenterology Research: Subject Areas, Impact, and Funding," Gut, 49, 295-302.

Maclean, M., DAVIES, C., Lewison, G., Anderson, J. (1998): "Evaluating the Research Activity and Impact of Funding Agencies," Research Evaluation, 7, 7-16.

PARTRIDGe, M. R., I. RIPPON, and G. LeWison (2003): "Who Funds Uk Respiratory Research?," Thorax, 58, 22-22.

Plerou, V., L. A. N. Amaral, P. Gopikrishnan, M. Meyer, and H. E. Stanley (1999): "Similarities between the Growth Dynamics of University Research and of Competitive Economic Activities," Nature, 400, 433-437.

SAlager-Meyer, F., M. A. A. Ariza, and M. P. Berbesi (2009): ""Backstage Solidarity" In Spanish- and English-Written Medical Research Papers: Publication Context and the Acknowledgment Paratext," Journal of the American Society for Information Science and Technology, 60, 307-317.

SAnDstrom, U. (2009): "Research Quality and Diversity of Funding: A Model for Relating Research Money to Output of Research," Scientometrics, 79, 341-349.

Tatsioni, A., E. Vavva, and J. P. A. IoAnnidis (2010): "Sources of Funding for Nobel Prize-Winning Work: Public or Private?," Faseb Journal, 24, 1335-1339.

ZHAO, D. Z. (2010): "Characteristics and Impact of Grant-Funded Research: A Case Study of the Library and Information Science Field," Scientometrics, 84, 293-306.

\section{Acknowledgements}

The author would like to thank the editor and two anonymous reviewers, his students and Dr Frederick Wheeler for their helpful comments. 
Figures

Figure 1 Box Plot of Cell Papers by Count of Funding Source and Times Cited

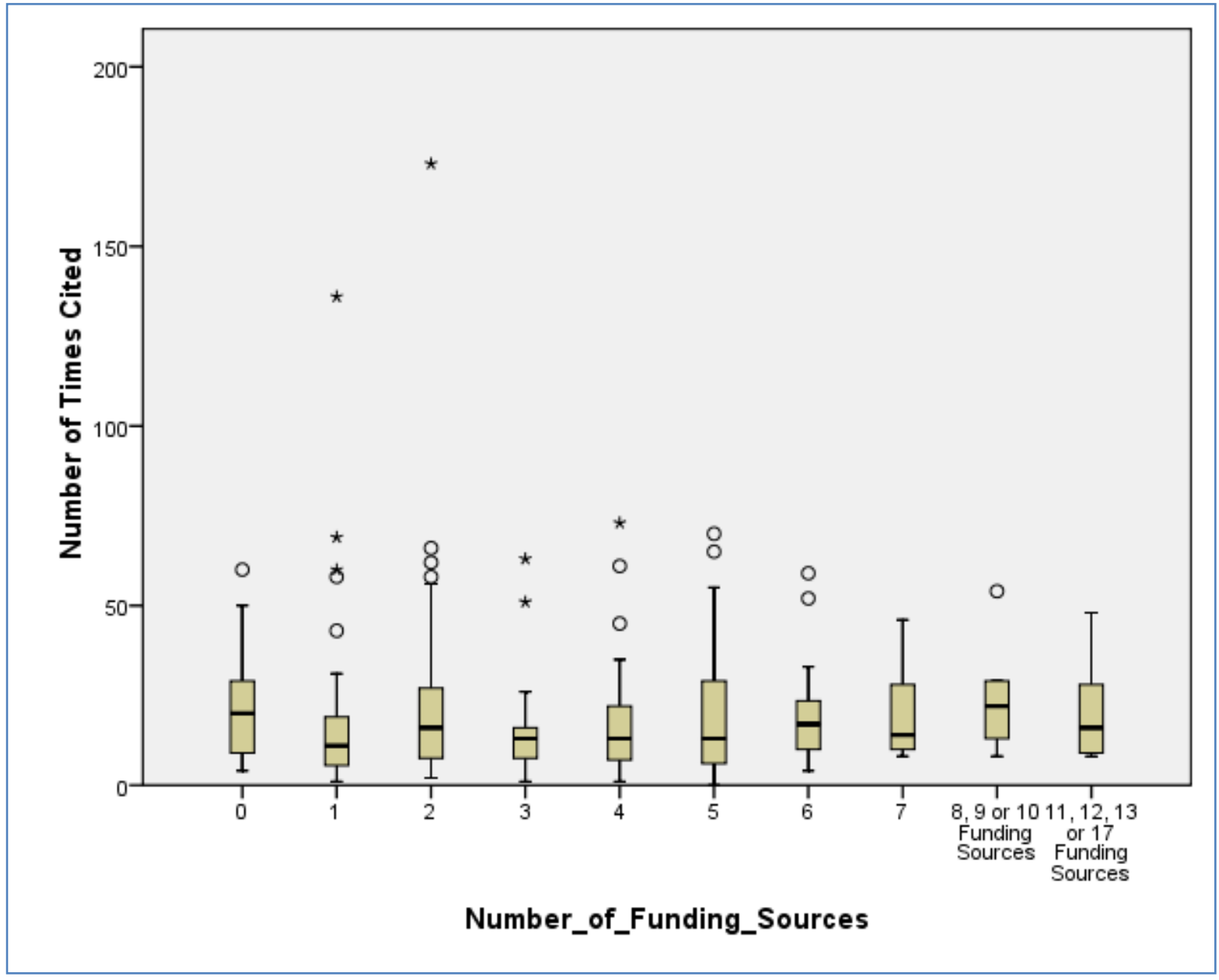

Figure 2 Box Plot of Physical Review Letter Papers by Count of Funding Source and Times Cited 


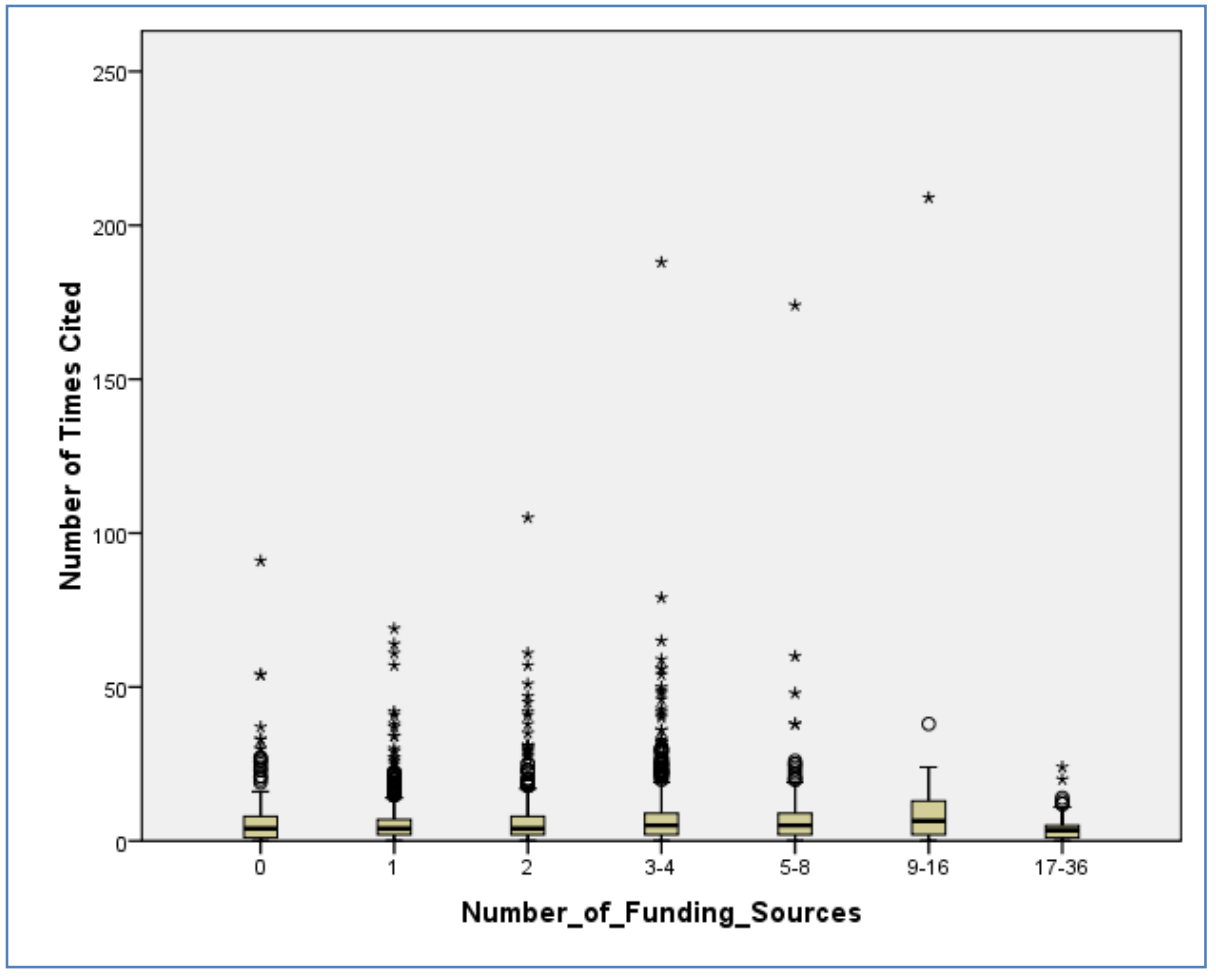


Tables

Table 1 - Kruskal Wallis Test of Ranks - Cell Papers

\begin{tabular}{|c|c|c|c|}
\hline \multicolumn{4}{|l|}{ Ranks } \\
\hline & Number_of_Funding_Sources & $\mathbf{N}$ & Mean Rank \\
\hline \multirow[t]{11}{*}{ Number of Times Cited } & 0 & 18 & 177.36 \\
\hline & 1 & 43 & 127.19 \\
\hline & 2 & 64 & 157.96 \\
\hline & 3 & 39 & 130.86 \\
\hline & 4 & 45 & 146.43 \\
\hline & 5 & 39 & 148.45 \\
\hline & 6 & 19 & 165.39 \\
\hline & 7 & 15 & 172.00 \\
\hline & 8,9 or 10 Funding Sources & 10 & 190.70 \\
\hline & $11,12,13$ or 17 Funding Sources & 9 & 174.22 \\
\hline & Total & 301 & \\
\hline
\end{tabular}

Table 2 Kruskal Wallis Test Statistic - Cell Papers

\begin{tabular}{|l|l|}
\hline \multicolumn{2}{|l|}{ Test Statistics ${ }^{\mathrm{a}, \mathrm{b}}$} \\
\hline & $\begin{array}{l}\text { Number of Times } \\
\text { Cited }\end{array}$ \\
\hline Chi-Square & 11.653 \\
\hline df & 9 \\
\hline Asymp. Sig. & .234 \\
\hline a. Kruskal Wallis Test \\
\hline $\begin{array}{l}\text { b. Grouping } \\
\text { Number_of_Funding_Sources }\end{array}$ \\
\hline
\end{tabular}


Table 3 Kruskal Wallis Test of Ranks - Physical Review Letters

\begin{tabular}{|l|l|l|l|}
\hline Ranks & $\begin{array}{l}\text { Number of Funding } \\
\text { Sources }\end{array}$ & N & Mean Rank \\
\hline \multirow{4}{*}{ Number of Times Cited } & 0 & 579 & 1603.76 \\
\cline { 2 - 4 } & 1 & 876 & 1582.93 \\
\cline { 2 - 4 } & 2 & 803 & 1708.33 \\
\cline { 2 - 4 } & $3-4$ & 830 & 1855.33 \\
\hline \multirow{5yy}{*}{$5-8$} & 240 & 1891.59 \\
\hline & $9-16$ & 42 & 1997.57 \\
\hline & $17-36$ & 44 & 1468.02 \\
\cline { 2 - 4 } & Total & 3414 & \\
\hline
\end{tabular}

Table 4 Kruskall Wallis Test Statistic - Physical Review Letters

\begin{tabular}{|l|l|}
\hline \multicolumn{2}{|l|}{ Test Statisticsa,b } \\
\hline & $\begin{array}{l}\text { Number } \\
\text { Times Cited }\end{array}$ \\
\hline Chi-Square & 54.091 \\
\hline df & 6 \\
\hline Asymp. Sig. & .000 \\
\hline a. Kruskal Wallis Test \\
\hline $\begin{array}{l}\text { b. Grouping Variable: Number } \\
\text { of Funding Sources }\end{array}$ \\
\hline
\end{tabular}

